\title{
Psychiatric illness and learning disability: a dual diagnosis
}

\section{Jane Bernal and Sheila Hollins}

The prevalence of moderate to profound learning disability is roughly 3 per 1000 and of mild learning disability about 3 per hundred (Abramowicz \& Richardson, 1975). There are estimated to be more than 120 million people with learning disability worldwide.

Most adults and children with learning disability do not live in hospitals but at home or in some type of residential accommodation. Psychiatric problems are fairly common, and learning disability can be thought of as a risk factor for psychiatric disorder. The presence of learning disability can alter presentation, and psychiatric diagnosis is likely to be based more on behavioural signs than on self-reported mental state.

\section{Definitions}

The Department of Health in England now uses the phrase people with learning disability. This is also preferred by those who have such disabilities. People with learning disabilities have made it clear that mental retardation, mental handicap and mental subnormality are as offensive as terms previously used, and contribute to social marginalisation. The names have often been changed but unless underlying social injustices are addressed each new term will become pejorative (Sinason, 1992).

The ICD and DSM classifications, and computer databases that follow international codings, still use the term mental retardation. In North America the preference is for the term developmental disabilities (Grossman, 1983).

The ICD-10 (World Health Organization, 1992) defines mental retardation as a condition of arrested or incomplete development of the mind, which is especially characterised by impairment of skills manifested during the developmental period, which contribute to the overall level of intelligence, i.e. cognitive, language, motor and social abilities. Retardation can occur with or without any other mental or physical disorder. However, the prevalence of other mental disorders is at least three to four times greater in this population than in the general population, and mentally retarded individuals are at greater risk of exploitation and physical, emotional and sexual abuse. Adaptive behaviour is always impaired, but in protected social environments this impairment may not be obvious in subjects with mild mental retardation.

A brief description of the level of function expected for each level of retardation is given. If standardised IQ tests are used, the levels fall within these ranges: $50-69$ is indicative of mild mental retardation; 35-49 of moderate retardation; 20-34 of severe, and below 20 of profound retardation.

The terms impairment, disability and handicap are often used interchangeably in everyday speech. In the WHO schedule they are not interchangeable.

In this context, an impairment is any loss or abnormality of psychological, physiological, or anatomical structure or function. A disability is any restriction or lack (resulting from impairment) of ability to perform an activity in the manner or within the range considered normal for a human being. A handicap is a disadvantage for an individual, resulting from an impairment or a disability, that limits or prevents the fulfilment of a role that is normal according to age, sex and social and cultural factors for that individual.

\section{"Challenging behaviour"}

This term was originally coined to draw attention to the interactive nature of the problem. Whether

Sheila Hollins is Professor of Psychiatry of Learning Disability and Head of the Division of Psychiatry of Disability, in the Department of Mental Health Sciences at St George's Hospital Medical School; Honorary Consultant Psychiatrist in Wandsworth Community Team for People with Learning Disability and Richmond, Twickenham and Roehampton Healthcare Trust; and Chairman of the Section for Psychiatry of Mental Handicap at the Royal College of Psychiatrists.

Jane Bernal is Senior Lecturer in Psychiatry of Disability, St George's Hospital Medical School. She works clinically as Honorary Consultant in Wandsworth Community Team for People with Learning Disability, seeing adults and some children with their families. 
or not a behaviour occurs or is perceived as challenging depends on features in the service as well as the individual.

Severely challenging behaviour refers to behaviour of such an intensity, frequency or duration that the physical safety of the person or others is likely to be placed in serious jeopardy, or behaviour which is likely to seriously limit or deny access to the use of ordinary community facilities (Emerson et al, 1991). The term challenging behaviour neither necessitates nor excludes a formal psychiatric diagnosis.

Depending on the definitions used, up to $7 \%$ of people with learning disabilities show behaviour that seriously disrupts their lives or that of those around them (Qureshi \& Alborz, 1992). Challenging behaviour is more common in people living in hospital or in their own homes than in local authority residential accommodation.

\section{Prevalence of psychiatric disorders}

Estimates vary according to the age and location of the populations studied, definitions of both psychiatric disorder and learning disability, and the instruments used. Studies show people with learning disabilities to have a significantly higher lifetime prevalence of psychiatric disorders (Table 1).

Studies based in mental handicap hospitals tend to show higher prevalence rates, probably because people with behavioural or psychiatric problems are more likely to be admitted to hospital, and they are harder to discharge. Hospitalisation may exacerbate problems especially in understaffed, poor quality institutions.

People with learning disability sent to hospital by the courts may not be typical of offenders with learning disability; for example, arson and sexual offences may be over-represented in hospital populations.

\section{Aetiology of psychiatric disorder in people with learning disability}

The aetiology of psychiatric disorder in people with learning disability can be understood in terms of dynamic interactions between biomedical and psychosocial processes.

\section{Biological}

Genetic. A number of disorders are linked to genetic causes.

Down's syndrome is significantly associated with Alzheimer's disease, both clinically and on neuropathology, and is also associated with depression (Collacott et al, 1992).

Tuberous sclerosis and various other conditions show higher than expected rates of autism and pervasive developmental disorders. It is not clear whether this is a specific association or whether it simply reflects overall brain damage.

Certain genetic syndromes have a very characteristic behavioural presentation (Holland, 1994; Turk \& Hill, 1995). Prader-Willi syndrome (partial deletion of Chromosome 15) is associated with overeating, a failure of satiety, and massive obesity. Lesch Nyhan syndrome (sex-linked recessive defect of uric acid metabolism) gives rise to selfinjurious behaviour.

It should be noted that most obesity and selfinjury that occurs in people with learning disability is not caused by these rare conditions.

Fragile $\mathrm{X}$ syndrome is the commonest cause of an X-linked learning disability. Men are more commonly affected, but women can have the syndrome. Some family members have learning disability with characteristic cognitive, language and social abnormality. Some but not all children with fragile $X$ meet criteria for the diagnosis of autism. The underlying genetic defect is a CGG repeat on the $X$ chromosome that can be detected using a gene probe. The length of the repeat determines the pattern of disability. Some affected family members present with emotional problems or psychiatric illness but no learning disability. Genetic screening is indicated when there is a family history of both learning disability and psychiatric illness.

It may be appropriate to offer genetic screening to adults who have not received an aetiological diagnosis in childhood.

Epilepsy. Epilepsy is common in people with learning disabilities (Corbett, 1988). It is associated with increased rates of psychiatric disturbance, probably due to a combination of neurological and social factors.

Physical illness. People who cannot communicate well may express themselves behaviourally if they are in pain or have chronic ill health. Symptoms such as anorexia and restlessness may be caused by infections or gastrointestinal disorders. Physical and psychiatric pathology may be difficult to distinguish. 
Table 1. Prevalence of psychiatric disorder in people with learning disabilities: epidemiological studies, adapted from Bregman (1991)

\begin{tabular}{|c|c|c|c|c|c|}
\hline Study & Age & Sample & Method & $\%$ psychiatric disorder & Controls \\
\hline $\begin{array}{l}\text { Rutter et al } \\
\text { (1970) }\end{array}$ & 9-11 & $\begin{array}{l}\text { Entire age cohort, } \\
\text { Isle of Wight }\end{array}$ & $\begin{array}{l}\text { Comprehensive } \\
\text { assessment, multiaxial }\end{array}$ & $30-42 \%$ & $6-7 \%$ \\
\hline $\begin{array}{l}\text { Gillberg et al } \\
\text { (1986) }\end{array}$ & $13-17$ & $\begin{array}{l}\text { Representative } \\
\text { cohort }\end{array}$ & Comprehensive, DSM-III & $\begin{array}{l}57 \% \text { (mild) } \\
64 \% \text { (severe) }\end{array}$ & $5 \%$ \\
\hline Jacobson (1982) & All ages & $\begin{array}{l}\text { Receiving services } \\
\text { for people with } \\
\text { MR in New York } \\
\text { State }\end{array}$ & $\begin{array}{l}\text { Survey of behaviour } \\
\text { frequency data }\end{array}$ & $\begin{array}{l}14 \% \text { (children) } \\
17 \% \text { (adults) }\end{array}$ & None \\
\hline Lund (1985) & $>20$ & $\begin{array}{l}\text { Sample from } \\
\text { Danish MR } \\
\text { register }\end{array}$ & Comprehensive, DSM-III & $27 \%$ & None \\
\hline Gostason (1985) & $20-60$ & $\begin{array}{l}\text { Sample from } \\
\text { Swedish register }\end{array}$ & Comprehensive, DSM-III & $\begin{array}{l}33 \% \text { (mild) } \\
71 \% \text { (severe) }\end{array}$ & $23 \%$ \\
\hline
\end{tabular}

Sensory impairment. Sensory impairment may cause disturbed behaviour or be a risk factor for psychiatric illness. About one in four adults with a learning disability has a significant hearing impairment and visual impairments are common (Wilson \& Haire, 1990).

Motor abnormalities. Tic-like phenomena and stereotypies are more common in people with known CNS damage. The phenomenology of Gilles de la Tourette's syndrome and the autistic spectrum disorders have been described, singly and together, in people with learning disability.

Prescribed medication. Drugs prescribed, for example, for epilepsy or disturbed behaviours, often have psychiatric and motor side-effects. Regular review of such prescriptions is often neglected (Wilson \& Haire, 1990). Sedative antiepileptic drugs (phenobarbitone, phenytoin) can produce drowsiness, paradoxical over-arousal or pseudo-dementia (Trimble, 1987). Vigabatrin may cause psychosis which can present as disturbed behaviour. People with learning disabilities may be particularly sensitive to the motor side-effects of neuroleptics, although apparently similar motor abnormalities also occur without neuroleptics (Rogers et al, 1991).

\section{Psychological}

Poor communication skills. Difficulties in understanding or in being understood may predispose to frustration, loss of motivation, challenging behaviour and psychiatric illness. Behaviour serving a communicative function may be wrongly attributed to psychiatric illness.

Limited range of coping behaviours. Impaired learning and restricted environments mean that people with learning disabilities acquire few coping skills, leaving them vulnerable to psychosocial stresses.

Low self-esteem. Some degree of parental loss and disappointment is common following the birth of a child with learning disabilities. Inability to keep up with other children and the experience of repeated failure at academic tasks, together with social marginalisation and stigmatisation, tend to interfere with the development of self-esteem. This is an established risk factor for depression.

Autism. Autistic spectrum disorders are much more common in people with learning disability than in the general population (Gillberg, 1990). This adds to the considerable body of evidence that autism has a neurodevelopmental rather than psychogenic basis. There is an increased prevalence of both 'Kanner' autism and of the severe social and language impairments described by Wing \& Gould (1979), which are common at lower IQ levels. The lack of a theory of mind postulated by Frith (1989) and others may explain the increased incidence of disturbed behaviour seen in people with autism. The inability to understand and predict the behaviour of others and everyday social 
rules often leads to disturbed behaviour and may predispose to psychiatric illness. Some of the psychiatric disturbance in this group may also be secondary to the underlying brain pathology (Gillberg, 1988; Rutter et al, 1994), the precise nature and cause of which has yet to be determined.

\section{Social}

Biological impairment. People who function at a very low level because of biological impairment are often unable to live independently or to find work. Their living expenses are often increased, but they tend to have low incomes both in child and adulthood.

Labelling. Being labelled may itself lower selfesteem and predispose to psychiatric illness. It may also lead to exclusion from opportunities for employment and an adequate income, leisure activities, marriage and a valued social role.

Arrangements for care. Most families continue to function well when they have a member who has a learning disability (Carr, 1985). Where family adjustment fails, or inadequate services are provided, people with learning disabilities may live in very unusual restrictive family circumstances. Residential care provision may fail to provide exposure to many normal learning experiences and be inappropriately tolerant of behaviour that would be unacceptable in people without disabilities. There is an increased likelihood of physical and sexual abuse among children and adults with learning disabilities (Sobsey et al, 1991), both at home and in service settings.

Loss. People who are dependent on others may be more vulnerable to the effects of loss, especially of a carer. Disturbed behaviour may follow loss life events but carers and others often deny that the person with learning disabilities is aware of the loss. The person with learning disability may thus be denied the opportunity to grieve. Such exclusion compounds the problem, delaying the person's understanding of the loss event and reducing the likelihood of them coming to terms with it.

Sexuality. The development of sexuality may also be denied by care givers (Craft et al, 1987). This may lead to someone being diagnosed as sexually deviant when in fact they have never been given any appropriate sexual knowledge.

\section{Psychiatric assessment and diagnosis}

The psychiatric assessment of a person with learning disabilities involves an assessment of their social circumstances, as well as history taking and examination, modified as necessary.

People with learning disability rarely present themselves to the doctor. Instead it is the concern of the family, or workers in care settings, that brings them to psychiatric attention. Assessment of the wider family and caring system as well is essential.

The history should be obtained both from the person with learning disabilities, if communication skills permit, and from an informant or informants.

Physical examination and investigations are particularly necessary in people who cannot complain or describe their symptoms. Pain or discomfort often present behaviourally. Hypothyroidism is associated with Down's syndrome and may mimic depression or dementia. Sensory assessment is important.

An informant can be asked to record target behaviours such as sleep or aggressive outbursts, to facilitate diagnosis. Recordings also permit monitoring of treatment, whether the intervention is behavioural, psychodynamic or pharmacological. Functional behavioural analysis is extremely useful.

Box 3. History-taking - points of interest

Mother's reproductive and obstetric history

Family history

Childhood - including milestones

Aetiology of the learning disability if known

How the family were told and how they responded

Highest level of functioning. Do not assume that a current low level of functioning is caused by the learning disability

Life events, especially changes of placement or staff, loss and abuse

Circumstances immediately before current problem

History of presenting complaint. Particular attention to behavioural correlates of psychiatric illness, e.g. sleep, appetite, level of activity, interest in previous pursuits (however limited) 


\section{Specific conditions}

Affective disorders. Major depressive disorder occurs and can be diagnosed at all IQ levels though the diagnosis is easily missed or simply seen as challenging behaviour. Depressive cognition and suicidal ideation are rare but anhedonia, changes in activity level or appetite and other biological symptoms can be used to make the diagnosis (Collacott et al, 1992). Both physical and psychological interventions can be used.

Mania also occurs, but should be differentiated from other causes of overactivity. Individualised recording schedules are particularly useful in managing cyclical disorders.

Schizophrenia. The relationship between schizophrenia, learning disability and autism has been a recurring debate in psychiatry (Turner, 1989). People with learning disability have a higher prevalence of schizophrenia (3-4\%) which tends to be inversely related to IQ. Schizophrenia cannot be diagnosed reliably below IQ approximately 45 (Reid, 1994). Below this level if there is evidence of delusions or hallucinations a diagnosis of psychosis not otherwise specified may be used.

Dementia. Pathological features of Alzheimer's disease are common in middle-aged people with Down's syndrome, as are deafness, hypothyroidism, cataracts and depression. It is particularly important to exclude treatable conditions in older people with learning disabilities who may develop physical health problems as they age (Moss et al, 1993; Day \& Jancar, 1994). These, like dementia, can present as loss of skills or disturbed behaviour. Psychometric diagnosis is difficult unless the results of adult, premorbid, testing are available.

Obsessive-compulsive disorder. Repetitive ritualised behaviour is common. It is often life long and associated with social impairment and language abnormalities: indeed, the presence of such behaviour is used in the diagnosis of autism. People with autism characteristically become very anxious if they are prevented from carrying out their rituals.

Adjustment reactions. People with learning disabilities are more vulnerable to the adverse effects of loss life events. The changes are often greater than for other people and denial often compounds the problem. The presentation may be behavioural. Counselling techniques, using pictures and objects as well as words are effective (Hollins \& Sireling, 1994). Prevention involves the education of families and services. People with autism need particularly careful management of change. Moves should be well planned and new staff introduced by careful steps (Howlin \& Rutter, 1987).

Post-traumatic stress disorder. Traumatic events, particularly abuse and accidental injury, may be followed by anxiety in or avoidance of similar situations, with flashbacks, nightmares and rumination over the event. In people who cannot talk this may present as sudden, otherwise inexplicable, changes in arousal; or avoidance of certain activities and obvious fear, in the presence of a history of trauma (Ryan, 1994). Treatment involves acknowledgement of the trauma, appropriate drug treatment and psychotherapy. Again, pictures may help (Hollins \& Sinason, 1992).

Autism. A diagnosis of autism does not preclude the diagnosis of other psychiatric disorders (except, according to some diagnostic schedules, obsessive-compulsive disorder). However, the motor phenomena, language pathology and social impairments of autism may lead to an overdiagnosis of schizophrenia. Prolonged episodes of severely disturbed behaviour may follow apparently trivial change or excessively demanding situations.

Hyperkineticlattention deficit disorder. Children with learning disability are more likely to develop attention deficit disorder and the disorder is more likely to persist into adult life. Stimulant drugs are thought to be less effective in children with learning disability. They are relatively contraindicated in Tourette's and autism where they may precipitate tics.

\section{Diagnostic guidelines}

Where there is no spoken or signed language it is not possible to diagnose delusions, hallucinations or obsessive-compulsive phenomena reliably. Even when there is language it may be impossible to distinguish between a wish, an overvalued idea, and a delusion; or between a daydream, a pseudohallucination and an hallucination. An interpreter who knows the client well is helpful.

Some instruments standardised on general psychiatric populations can be used in people with mild learning disability and specialist research instruments are being developed. At the moment the use of standardised clinical instruments is much less well developed than it is for other psychiatric populations (Sturmey et al, 1991; O'Brien, 1992). 
A concise diagnostic label is not always possible. It may be better to describe the symptoms and the setting in which they are occurring. A multi-axial classification proposed by a working party of the Royal College of Psychiatrists (Box 2) was developed from the ICD-10 system, roughly corresponding to that used in child psychiatry, when a single diagnosis is inadequate to describe the total situation (Anness, 1991).

\section{Intervention, treatment and management}

Assessment for treatment, treatment itself, and checking the effectiveness of treatment, should be multi-disciplinary and requires good interprofessional communication. Parents and providers of social care should be involved in decisionmaking unless this would breach confidentiality. A communicable plan of management should always be attainable.

Many people with learning disabilities will be able to consent or withhold consent to medical procedures especially if the information is carefully presented. Some will not be able to consent either because they can not understand the implications or because they are not able to make a free choice (Curran \& Hollins, 1994). If an adult is not able to consent no other person (in English law) can consent on their behalf, and treatment decisions are based on the duty of care that doctors owe their patients and their obligation to act in the patient's best interests. It is good practice to consult all those concerned with the care of the patient.

Behavioural treatments, based on functional behavioural analysis, have been shown to be effective in managing, reducing, or eliminating challenging behaviour such as aggression or selfinjury in individuals (Emerson, 1993). Most studies have been done in staffed settings. Less information is available about other psychological methods. Rational emotive therapy, cognitive therapy and individual and group psychotherapies have all been described. Evaluation of psychotherapy outcomes is similar to that seen in other groups (DesNoyes Hurley, 1989; Hollins \& Evered, 1990).

\section{Medication}

Due to the underlying neuropathology drug treatment is always to some extent a therapeutic trial and particularly careful monitoring of sideeffects is essential. Ineffective medication should be discontinued and long-term treatment regularly
Box 2. Multi-axial classification (Anness, 1991)

1. Life context - home, family, occupation

2. Cognitive level-IQ if available, specify test used and date. Mental age (e.g. are some of his behaviours like those of a toddler who is still learning by doing rather than learning by seeing or thinking?)

3. Developmental disorders, e.g. specific speech and language difficulties and other developmental delays.

4. Organic factors, including aetiology of original handicap, neurological diagnosis, genetic syndrome and concurrent illnesses

5. Psychosocial factors including social environment, friendships, and quality of relationship

6. Psychiatric and behavioral state including changes in mood or thought processes, behavioural disturbances such as self-injury or sleeplessness, understand ing of handicap, insight, self-esteem

7. Functional abilities, including self-care and communication

reviewed (Einfeld, 1990; Sovner \& DesNoyes Hurley, 1992).

There is evidence that long-term neuroleptics are overprescribed for behavioural indications, and that other effective drug regimes, such as serotonin re-uptake inhibitors are under-used, often because no diagnostic formulation has been attempted.

Tricyclic antidepressants and SSRIs may be used to treat depression. Clomipramine and fluoxetine may also lessen distressing repetitive behaviour in people with autism.

Phenothiazines, butyrophenones and the newer antipsychotic drugs are all used in schizophrenia. People with learning disability may be particularly vulnerable to motor side-effects. Neuroleptics should be avoided as a treatment for behavioural disorders wherever possible.

Carbamazepine and valproate are usually the drugs of first choice for epilepsy. Phenobarbitone and phenytoin contribute to learning problems and may precipitate over arousal or pseudo-dementia. There are few controlled trials of the newer antiepileptic drugs in this population. Both vigabatrine (despite adverse behavioural side-effects) and lamotrigine have been shown to improve seizure control in people with learning disabilities. 


\section{Service organisation}

In 1993 the Department of Health published a report called Services for People with Learning Disabilities and Challenging Behaviour or Mental Health Needs (Mansell, 1993) and in 1994 clarified it further by reaffirming the continuing important role of the specialist psychiatrist in learning disability. The report had two main themes: (a) that direct care staff need to be well trained and supported to be able to understand and respond to challenging behaviour and mental health needs and (b) that specialist health-care skills are needed locally to support and train direct care staff, and to serve those people with the most challenging needs. Both purchasers and providers of mental health services should be aware of the actual recommendations of the report.

The separation of many specialist health care services, including specialist mental health services, for people with learning disabilities into different NHS Trusts from the rest of psychiatric practice will make close working relationships harder. Many consultants in this speciality are single-handed and welcome being more fully included within the psychiatric fraternity, so that their expertise can be better understood.

Department of Health Advisory Group Statement, 1994

Specialist psychiatrists in mental handicap have a continuing role both in multidisciplinary community teams and in inpatient settings

The gap between general mental health services and mental health services for people with learning disability should be reduced

Purchasers should ensure that specialist (learning disability) mental health services are available for those people with learning disability who need them

\section{References}

Abramowicz, H. K. \& Richardson, S. A. (1975) Epidemiology of severe mental retardation in children: community studies. American Journal on Mental Retardation, 80, 18-39.

Anness, V. (1991) A multi-aspect assessment for people with mental handicap. Psychiatric Bulletin, 15, 146.

Carr, J. (1985) The effect on the family of a severely mentally handicapped child. In Mental Deficiency: The Changing Outlook (eds A. M. Clarke, A. D. B. Clarke \& J. M. Berg), pp. 512-548. London: Methuen.
Box 3. Current controversies in service provision

The future role of the mental handicap hospital

The role of the general psychiatrist in the treatment of people with learning disability

Linked posts in psychiatry of mental handicap and general psychiatry

Specialist psychiatric teams vo multidisciplinary teams

Lifespan v. adult-only services

The extent to which health services should provide residential and day care

The treatment of the offender in learning disability

Collacott, R.A. Cooper, S. A. \& McGrother, C. (1992) Differential rates of psychiatric disorders in adults with Down's syndrome compared with other mentally handicapped adults. British Journal of Psychiatry, 161, 671-674.

Corbett, J. (1988) Some special problems of epilepsy. In $A$ Textbook of Epilepsy (eds J. Laidlaw, A. Richens \& J. Oxley), pp. 533-538. Edinburgh: Churchill Livingstone.

Craft, A., Heshuis, L., Johnson, P. J., et al (1987) Mental Handicap and Sexuality: Issues and Perspectives. Tunbridge Wells: Costello.

Curran, J. \& Hollins, S. (1994) Consent to medical treatment and people with learning disability. Psychiatric Bulletin, 18, 691-693.

Day, K. \& Jancar, J. (1994) Mental and physical health and ageing in mental handicap: a review. Journal of Intellectual Disability Research, 38, 241-256.

DesNoyers Hurley, A. (1989) Individual psychotherapy with mentally retarded individuals: a review and call for research. Research in Developmental Disabilities. 10, 261-275.

Einfeld, S. L. (1990) Guidelines for the use of psychotropic medication in individuals with developmental disabilities. Australian and New Zealand Journal of Developmental Disabilities, 16, 71-73.

Emerson, E. (1993) Challenging behaviours and severe learning disabilities: recent developments in behavioural analysis and intervention. Behavioural and Cognitive Psychotherapy, 21, 171198.

- Cambridge, P. \& Harris, P. (eds)(1991) Evaluating the Challenge. A Guide to Evaluating Services for People with Learning Difficulties and Challenging Behaviour. London: King's Fund Centre.

Frith, U. (1989) Autism Explaining the Enigma. Oxford: Basil Blackwell.

Gillberg, C. (1988) The neurobiology of infantile autism. Journal of Child Psychology and Psychiatry, 29, 257-266.

(1990) Autism and pervasive developmental disorders. Journal of Child Psychology and Psychiatry, 31, 99-120.

Grossman, H. J. (ed)(1983) Classification in Mental Retardation. Washington, DC:American Association on Mental Deficiency.

Hollins, S. \& Evered, C. (1990) Group process and content: the challenge of mental handicap. Group Analysis, 23, 56-67.

\& Sireling, L. (1994) When Mum Died and When Dad Died. London: St George's Mental Health Library.

_ \& Sinason, V. (1992) Jenny Speaks Out and Bob Tells All. London: St George's Mental Health Library.

Howlin, P \& Rutter, M. (1987) Treatment of Autistic Children. Chichester: John Wiley.

Mansell, J. L. (1993) Services for People with Learning Disabilities and Challenging Behaviour or Mental Health Needs. London: HMSO.

Moss, S., Goldberg, D., Patel, P., et al (1993) Physical morbidity 
in older people with moderate, severe and profound mental handicap, and its relation to psychiatric morbidity. Social Psychiatry and Psychiatric Epidemiology, 28, 32-39.

O'Brien, G. (1992) Behavioural phenotypy in developmental psychiatry. Measuring behavioural phenotypes - a guide to available schedules. European Child and Adolescent Psychiatry, supp. 1, 1-61.

Qureshi, H. \& Alborz, A. (1992) Epidemiology of challenging behaviour. Mental Handicap Research, 5, 130-145.

Reid, A. H. (1994) Psychiatry and learning disability. British Journal of Psychiatry, 164, 613-618.

Rogers, D., Karki, C., Bartlett, C., et al (1991) The motor disorder of mental handicap: an overlap with the motor disorders of severe psychiatric illness. British Journal of Psychiatry, 158, 97102.

Rutter, M., Bailey, A., Bolton, P., et al (1994) Autism and known medical conditions: myth and substance. Journal of Child Psychology and Psychiatry, 35, 311-322.

Ryan, R. (1994) Post-traumatic stress disorder in persons with developmental disabilities. Community Mental Health Journal, Feb.

Sinason, V. (1992) Mental Handicap and the Human Condition. London: Free Association Books.

Sobsey, D., Gray, S., Wells, D., et al (1991) Disability, Sexuality and Abuse : an annotated bibliography. Baltimore: Paul. $\mathrm{H}$. Brookes.

Sovner, R. \& DesNoyers Hurley, A. (1992) The diagnostic treatment formulation for psychotropic drug therapy. The Habilitative Mental Healthcare Newsletter, 11, 81-89.

Sturmey, P., Reed, J. \& Corbett, J. (1991) Psychometric assessment of Psychiatric disorders in people with learning difficulties (mental handicap): a review of measures. Psychological Medicine, 21, 143-155.

Trimble, M. (1987)Anticonvulsant drugs and cognitive function: a review of the literature. Epilepsia, 28 (suppl 3), S37-S45.

Turk, J. \& Hill, P. (1995) Behavioural phenotypes in dysmorphic syndromes. Clinical Dysmorphology (in press).

Turner, T. H. (1989) Schizophrenia and mental handicap: an historical review, with implications for further research. Psychological Medicine, 19, 301-314.

Wilson, D. N. \& Haire, A. (1990) Health care screening for people with mental handicap living in the community. British Medical Journal, 301, 1379-1381.

Wing, L. \& Gould, J. (1979) Severe impairments of social interaction and associated abnormalities in children: epidemiology and classification. Journal of Autism and Developmental Disorders, 9, 11-30.

World Health Organization (1992) The ICD-10 Classification of Mental and Behavioural Disorders. Geneva: WHO.

\section{Suggested reading}

ARC \& NAPSAC (1993) It Could Never Happen Here! The Prevention and Treatment of Sexual Abuse of Adults with Learning Disabilities in Residential Settings. Nottingham: ARC \& NAPSAC.

Department of Health (1994) Specialist Mental Health Services for people with learning disabilities. Advisory Group on Behavioural Disturbance and Mental Health. Services Developments for people with Learning Disabilities, Rm 122, Wellington House, London SE1 8 UG

Gillberg, C., Persson, E., Grufman, M., et al (1986) Psychiatric disorders in mildly and severely mentally retarded urban children and adolescents: epidemiological aspects. British Journal of Psychiatry, 149, 68-74.

Gostason, R. (1985) Psychiatric illness among the mentally retarded: a Swedish population study. Acta Psychiatrica Scandinavica, 71 (suppl. 318), 1-117.

Hogg, J. \& Raynes, N. V. (eds)(1987) Assessment in Mental Handicap - A Guide to Assessment Practices, Tests and Checklist. London: Croom Helm.

Holland, A. J. (1994) Learning disability and psychiatric/ behavioural disorders: a genetic perspective. In The New Genetics of Mental Illness (eds P. McGuffin \& R. Murray), pp. 245-258.

Jacobson, J. (1982) Problem behaviour and psychiatric impairment within a developmentally disabled population.
I: Behaviour frequency. Applied Research in Mental Retardation, 3, 121-140.

Lund, J. (1985) The prevalence of psychiatric morbidity in mentally retarded adults. Acta Psychiatrica Scandanavica, 72, 563-570.

Russell, O. (1985) Mental handicap. In Current Reviews in Psychiatry No 1. London: Churchill Livingstone.

Rutter, M., Graham, P. \& Yule, W. (1970 ) A neuropsychiatric study in childhood. In Clinics in Developmental Medicine, vol 35 and 36. London: Heinemann Medical Books.

Thompson, D. (1993) Learning Disabilities: The Fundamental Facts. London: Mental Health Foundation.

\section{Multiple choice questions}

1 Depression in people with learning disability

a commonly produces suicidal ideation

b is never treated with SSRIs

c can be monitored by behavioural charting

d may follow loss life events

e can only be diagnosed above IQ 45

2 Psychotropic drug prescriptions for people with learning disability

a should be regularly reviewed

b are rarely used

c neuroleptics have fewer motor side-effects in this population

d can be monitored behaviourally for effectiveness

e should be prescribed for a specific indication

3 When giving psychotherapy for people with learning disability

a behavioural interventions have been shown to be effective

b group psychotherapy cannot be used

c dynamic psychotherapy has never been used

d it may be needed after sexual abuse

$e$ is easier to evaluate for effectiveness than in people with no disability

\section{Down's syndrome}

$a$ is associated with hypothyroidism

b is a risk factor for depression in middle age

c always causes loss of skills

d is associated with Alzheimer's disease

e seldom produces deafness

\begin{tabular}{|c|c|c|c|}
\hline \multicolumn{4}{|c|}{ MCQ answers } \\
\hline 1 & 2 & 3 & 4 \\
\hline a $F$ & a $T$ & a $T$ & a $T$ \\
\hline b F & b F & b F & b $\mathbf{T}$ \\
\hline c $T$ & c $\mathrm{F}$ & c $F$ & c $F$ \\
\hline d $\mathbf{T}$ & d $T$ & d $\mathbf{T}$ & d $\mathbf{T}$ \\
\hline e $F$ & e $T$ & e $F$ & e $F$ \\
\hline
\end{tabular}

